\title{
Hannah Arendt: considerações sobre a Revolução Americana'
}

\section{Hannah Arendt: considerations on the American Revolution}

\author{
José João Neves Barbosa Vicente \\ https://orcid.org/0000-0001-6823-3933 - E-mail: josebvicente@bol.com.br
}

\begin{abstract}
RESUMO
A revolução, para Hannah Arendt, é um acontecimento cujo objetivo é fundar um novo corpo político onde a liberdade possa aparecer. Em seu livro Da revolução, ela analisa e contrapõe as experiências americana e francesa, defendendo que, enquanto a primeira foi um "sucesso", a segunda foi um grande "fracasso". O objetivo deste artigo é analisar e expor o modo como Hannah Arendt compreendeu esse "sucesso" da Revolução Americana.
\end{abstract}

Palavras-chave: Arendt. Fundação. Liberdade. Política. Revolução Americana.

\begin{abstract}
The Revolution, for Hannah Arendt, is an event whose goal is to establish a new political body where freedom can appear. In her book On the Revolution, she analyzes and counteracts the American and French experiences, defending that while the first was a "success", the second was a great "failure". The aim of this article is to analyze and expose the way Hannah Arendt understood this "success" of the American Revolution.
\end{abstract}

Keywords: Arendt. Foundation. Freedom. Policy. American Revolution.

Ao longo da sua trajetória intelectual, Hannah Arendt analisou, refletiu e discutiu com profundidade e rigor vários temas e acontecimentos relacionados ao pensamento ocidental, entre eles, destacam-se, no presente artigo, as revoluções que, para ela, são ações dos homens

${ }^{1}$ O conteúdo deste artigo é parte da pesquisa realizada pelo autor no curso de pós-graduação na UFBA, sob a orientação do professor Dr. Genildo Ferreira da Silva. 
cujo objetivo é a criação de um novo corpo político capaz de garantir espaço no qual a liberdade possa aparecer. Ao analisar esses acontecimentos, principalmente em sua obra Da revolução, Hannah Arendt contrapõe basicamente duas experiências: a Americana (ocorrida no verão de 1776, na Filadélfia) e a Francesa (ocorrida no verão de 1789, em Paris). A primeira, aos seus olhos, foi um "sucesso", conseguiu fundar, de fato, um "novo corpo político"; a segunda, por sua vez, foi um grande "fracasso", não conseguiu atingir o objetivo. Neste artigo, no entanto, a finalidade não é analisar e nem discutir a Revolução Francesa que, para Hannah Arendt, fracassou porque não conseguiu criar condições para a "liberdade", ou seja, no lugar da "liberdade" colocou a "necessidade" como principal característica do pensamento político. Aqui o alvo principal são as considerações da autora sobre a Revolução Americana e, em especial, sua afirmação de que esse acontecimento foi um "sucesso", apesar de nem tudo ter acontecido como foi pensado e planejado pelos homens da Revolução.

A Revolução Americana, como compreendida por Hannah Arendt, não foi um acontecimento que fez história no mundo, como aconteceu, por exemplo, com a Revolução francesa, ela permaneceu como um evento de importância quase que local e nunca conseguiu arrastar para o seu lado argumentos e plausibilidades suficientes para prevalecer na tradição da revolução. Isso, no entanto, não significa dizer que a Revolução Americana não teve "a cultura livresca e o pensamento conceitual" como seus arcabouços; a verdade é que o "interesse pelo pensamento e teorias políticos se esgotou logo após a tarefa ter sido realizada", e isso contribuiu em larga medida, para que essa revolução permanecesse "estéril em termos de política mundial." (ARENDT, 1988, p. 175). Mesmo assim, de acordo com Hannah Arendt, ela foi a única que teve "sucesso"; apenas a Revolução Americana conseguiu fundar, de fato, um "novo corpo político" com o objetivo de possibilitar a participação, a deliberação e a discussão. Em outras palavras, apenas ela conseguiu fundar um espaço de aparência no qual os homens ganham importância através de seus discursos e de suas ações.

Esse sucesso, no entanto, não se deve apenas à sabedoria dos "Pais Fundadores", mas principalmente à ausência do"estado de pobreza"no cenário americano. A Revolução Americana "ocorreu em um país que desconhecia completamente a difícil situação da miséria popular." (ARENDT, 1988, p. 125); um país que se tornou "o símbolo de uma sociedade sem pobreza antes da Idade Moderna", principalmente devido ao "seu desenvolvimento tecnológico único" que lhe possibilitou descobrir"os meios de abolir aquela miséria abjeta de pura indigência, que sempre fora considerada como eterna." (ARENDT, 1988, p. 19). Na América, portanto, diferente da Europa (principalmente na França), não existia "a miséria e a escassez". Hannah Arendt reconhece que o sentimento de compaixão por aqueles que sofriam de miséria e escassez perseguiu e motivou "os melhores homens de todas as revoluções", mas na Revolução Americana esse tipo de sentimento "não desempenhou nenhum papel na motivação dos atores"; em torno dos protagonistas da revolução Americana, "não existia nenhum sofrimento que pudesse ter despertado suas paixões, nem carências avassaladoramente prementes que os levassem a submeter-se à necessidade, nem piedade para desviá-los da razão." (ARENDT, 1988, p. 75).

A situação dos pobres, por exemplo, como percebida por John Adams, uma figura chave entre os homens da Revolução Americana, não foi encarada em termos de uma massa sofredora que despertaria a compaixão e desviaria o rumo da revolução, mas enxergada em termos de "obscuridade", ou seja, na visão de John Adams, "a obscuridade, mas do que a penúria, é a maldição da pobreza." (ARENDT, 1988, p. 55). Uma situação ainda mais obscura do que a dos pobres, era a situação dos escravos, mas também não teve um papel significativo na Revolução; para os americanos, a "escravidão" nunca fez "parte da questão social"; era simplesmente como se ela "não existisse, o que tornava também inexistente a mais poderosa e talvez a mais devas- 
tadora das paixões que arrebatam os revolucionários, a paixão da compaixão." (ARENDT, 1988, p. 57). Na América os trabalhadores não eram "miseráveis" e, por conseguinte, não eram movidos pela "necessidade", por isso "a revolução não foi frustrada por eles". Nesse sentido, no cenário americano o problema colocado pelos homens da revolução não foi "de ordem social, mas político, e dizia respeito não à ordem da sociedade, mas à forma de governo." (ARENDT, 1988, p. 54-55). Em outras palavras, a Revolução Americana foi política e não social.

Sem qualquer preocupação com a libertação do povo dos grilhões da necessidade e da escassez, uma vez que esse tipo de problema já estava resolvido na sociedade americana da época, os revolucionários prescindiram-se da violência e concentraram suas atenções no objetivo próprio da revolução: a fundação de um novo corpo político capaz de assegurar o espaço onde a liberdade possa aparecer. Entre todas as revoluções "típicas da era moderna" e seus entusiasmos "pela fundação de um novo corpo político", apenas a Revolução Americana não glorificou "a violência como único meio de 'fazer' esse corpo." (ARENDT, 2009a, p. 240). No contexto da Revolução Americana, em nenhum momento ou fase os revolucionários sequer cogitaram usar a força para "inverter os papeis de governantes e governados"; assim, em sua essência, a Revolução Americana foi basicamente "um choque de ideias, pura e simples." (WINTERS, 1987, p. 197-198). Os revolucionários americanos, como observou Hannah Arendt, "permaneceram homens de ação do princípio ao fim, da Declaração da Independência à organização da Constituição." (ARENDT, 1988, p. 75). O rumo da revolução nunca foi desviado do seu curso e o seu comprometimento firme e decidido "com a implantação da liberdade e o estabelecimento de instituições duradouras" sempre prevaleceu "e, àqueles que atuavam nessa direção, nada era permitido que estivesse fora do âmbito da lei civil." (ARENDT, 1988, p. 73).

Ao longo do seu curso, a Revolução Americana sempre foi clara em sua linguagem e em seu propósito. Para os seus protagonistas, "não era o constitucionalismo no sentido 'limitado"', mas o governo legítimo que ocupava "suas mentes." (WILKINSON, 2012, p. 42). Em nenhum momento, como destacou Hannah Arendt, cogitou-se colocar a questão fundamental em termos de "como limitar o poder, mas como estabelecê-lo", ou em outras palavras, a preocupação principal desses homens não era "como limitar o governo, mas como fundar um novo." (ARENDT, 1988, p. 118). Todos eles estavam plenamente cionscintes de que para o aparecimento da liberdade, nao bastava apenas ser liberto da miséria e da opressão, mas era necessário algo mais e maior. A liberdade, além da "companhia de outros homens", precisava também "de um espaço público comum ", ou seja, de "um mundo politicamente organizado" onde "cada homem livre poderia inserir-se por palavras e feitos." (ARENDT, 1972, p. 194). Aqueles que se envolveram diretamente no processo da revolução, não apenas sabiam, mas concordavam plenamente com a ideia de que "o plano político, numa república, se constituía numa troca de opiniões entre iguais", todos eles estavam também cientes que esse plano "desapareceria no mesmo instante em que esse intercâmbio se tornasse supérfluo, se por acaso todos os iguais fossem da mesma opinião." (ARENDT, 1988, p. 74).

Portanto, em nenhum momento do percurso da Revolução Americana, seus protagonistas "se referiram em seus argumentos, à opinião pública [...] para reforçar suas próprias opiniões", os homens da revolução entenderam desde o início "que o domínio da opinião pública era uma forma de tirania." (ARENDT, 1988, p. 74). Na América, a revolução deu origem aos Estados Unidos, e a existência da "república" não se deu, por exemplo, "em função de alguma 'necessidade histórica' ou de algum desenvolvimento orgânico", ela ocorreu "em consequência de um ato deliberado e intencional: a fundação da liberdade." (ARENDT, 1988, p. 173). Assim, de acordo com Hannah Arendt, desde a crise do mundo moderno, cuja origem encontra-se basicamente no declínio da trindade romana de religião, tradição e autoridade que dava suporte aos 
assuntos humanos e servia de fundamento à comunidade política, de todas as tentativas no sentido de fundar um novo corpo político, apenas a Revolução Americana alcançou êxito, apenas ela "foi bem sucedida". Apenas na América "os pais fundadores" conseguiram, de fato, fundar "um organismo político inteiramente novo prescindindo da violência e com o auxílio de uma Constituição." (ARENDT, 1972, p. 185).

Decididos desde o inicio em atingir o objetivo da revolução, a saber, a fundação de um novo corpo político no qual a liberdade possa se manifestar, e cuja autoridade não seria jamais "um Legislador Imortal", "uma verdade autoevidente, ou qualquer outra fonte transcendente e extraterrena", mas sim "o próprio ato de fundação", os homens da Revolução Americana em nenhum momento se sentiram "tentados a atribuir a mesma origem à lei e ao poder"; na verdade, eles estavam convencidos de que "o fundamento do poder era o povo, mas a fonte da lei devia ser a constituição", isto é, um documento escrito, durável e que não podia ser abordado de um único ponto de vista, mas de "diferentes ângulos"; um documento sujeito a várias "interpretações", passível de ser mudado ou reformulado de acordo com "as circunstâncias", mas sem jamais se tornar "um estado de espírito subjetivo, como a vontade" (ARENDT, 1988, p. 125-126; 164); esse documento devia permitir a participação de todos no espaço público através de atos e palavras. Hannah Arendt visualiza, assim, na Revolução Americana que lutou pela liberdade política e não pela libertação da opressão e exploração social, aquela paixão pelo espaço público vivenciada na polis grega que multiplicava "para cada homem as possibilidades de distinguir-se, de revelar em atos e palavras sua identidade singular e distinta." (ARENDT, 2009a, p. 210). Essa característica presente nessa revolução, de acordo com Hannah Arendt, encontra sua explicação mais clara na "experiência" dos americanos, isto é, os revolucionários já tinham percebido que "os habitantes das colônias" participavam das "assembleias" por amor à discussão e à distinção.

Para os homens da Revolução Americana, a constituição como foi pensada por eles, "não é o ato de um governo, mas de um povo que constitui um governo." (PAINE apud ARENDT, 1988, p. 116). Essa afirmação, de acordo com as observações feitas por Parekh, deve ser entendida nos seguintes termos: "a constituição representa as condições sobre as quais a comunidade política é constituída e que o cidadão deve aceitar para se tornar seu membro." (PAREKH, 1981, p. 164). Ela é, portanto, mais do que um documento escrito que prescreve o que o governo e os cidadãos podem ou não fazer, ela é, na verdade, o alicerce sobre o qual os Estados Unidos da América foram fundados como uma nação a partir de um evento político, a saber, a revolução. Como disse Lang, para Hannah Arendt, a criação da constituição americana deve ser compreendida no sentido aristotélico de estrutura de governo, não como simples pedaço de papel que "encarna a ação política corporativa" (LANG, 2005, p. 186). No momento da fundação da república os homens demonstraram um poder que só pode surgir através de um agir em conjunto; "para eles, o poder surgiu quando e onde o povo passou a se reunir e a se vincular através de promessas, pactos e compromissos mútuos." (ARENDT, 1988, p. 146).

A criação da constituição que garante a permanência do ato de fundação que se transmite a cada nova geração foi, sem dúvida, o grande marco da Revolução Americana e, sem dúvida, a grande medida do seu sucesso está no culto e na adoração desse documento escrito. A Revolução Americana "obteve êxito", exatamente onde todas as demais fracassaram; ela conseguiu "fundar um novo corpo político suficientemente estável para sobreviver ao violento assédio dos séculos futuros" que começou a se tornar realidade no "instante em que a Constituição começou a ser 'adorada"'. Portanto, a diferença fundamental entre a Revolução Americana e todas as outras revoluções, não está na "crença" em um "legislador imortal", nas "promessas de recompensas", nas "ameaças de punição" ou no "duvidoso caráter axiomático das verdades enumeradas no preâmbulo da Declaração de Independência, que assegurou estabilidade à nova república", mas sim na 
"autoridade contida no próprio ato de fundação." (ARENDT, 1988, p. 159). De acordo com observações de Amiel, a novidade trazida pelos homens da revolução com a criação da constituição pode ser dividida em três pontos essenciais: estruturações do poder com o federalismo, da autoridade com a Suprema Corte e da opinião com o Senado. Em relação ao poder, os homens da revolução não o confundiram com a lei e nem confundiram as origens de ambos. Enquanto o poder se fundamenta no povo, a fonte da lei encontra-se alicerçada na constituição, um texto mundano, durável e estável, jamais na vontade. (AMIEL, 1997, p. 110-117; 2003, p. 54-86).

Seguindo o exemplo romano, Hannah Arendt observa que os homens da Revolução Americana incorporaram também a autoridade à instituição política, mas com sua sede na Suprema Corte; para os revolucionários, essa autoridade "é exercida através de uma formulação contínua da Constituição, pois a Suprema Corte é, de fato, nas palavras de Woodrow Wilson, 'uma espécie de assembleia constitucional em sessão permanente". Portanto, diferente do que acontecia em Roma onde "a função da autoridade era política, e consistia em oferecer aconseIhamento", na República americana "a função da autoridade é legal, e se exerce através da interpretação" pela Suprema Corte (ARENDT, 1988, p. 161). A "autoridade da Constituição americana repousa em sua inerente capacidade de ser emendada e ampliada", nesse sentido, ela se expande e agrega novos temas de interesse dos homens que ingressarão no mundo após o ato de fundação (ARENDT, 1988, p. 162). É, portanto, a partir dessas observações de Hannah Arendt que King conclui em seus estudos sobre esse tema, que a autora "viu a Revolução Americana como uma revolução genuinamente política que trouxe algo novo ao mundo político, ainda que isso se devesse, em grande medida, ao precedente romano." (KING, 2015, p. 96).

Ao lado da Suprema Corte que garante a estabilidade e a durabilidade do novo corpo político, o Senado protege e coloca em relevo a "opinião". Considerada pelos homens da Revolução Americana como sendo imprescindível para a democracia, na medida em que ela só pode ser formada na pluralidade e na diversidade, a opinião ganha o seu espaço no coração da política. Sempre individual e fruto do diálogo livre entre os homens, a opinião é transformada em opinião pública pelo Senado. Entre todas as revoluções, a Americana foi a única que "soube como criar uma instituição duradoura para a formação pública de opiniões dentro da própria estrutura da República" (ARENDT, 1988, p. 182). Com a Suprema Corte e o Senado, respectivamente "uma instituição duradoura para o julgamento" e "uma instituição duradoura para a opinião", os Pais Fundadores "transcenderam sua própria estrutura conceitual" e colocaram em relevo as "faculdades" do juízo e da opinião, "as mais importantes do ponto de vista político" e que "haviam sido quase totalmente negligenciadas pelas tradições do pensamento político e filosófico." (ARENDT, 1988, p. 183). E, para Hannah Arendt, se esses homens da Revolução Americana conseguiram, de fato, "transcender a estreita e tradicional estrutura de suas concepções básicas e gerais", é porque neles existiam não apenas um "premente desejo de conferir estabilidade" à uma "nova criação", mas também "de sedimentar, numa 'instituição duradoura', todos os fatores da vida política." (ARENDT, 1988, p. 183).

Toda a análise da Revolução realizada por Hannah Arendt, como observou Adverse (2012), se encaixa perfeitamente em sua compreensão da "república" fruto da "clássica oposição entre governo monárquico - no qual a concentração do poder coloca o soberano acima das leis - e governo republicano - que pode ser também caracterizado como o governo das leis". Nesse sentido, para ela, a "república" não pode deixar de ser uma "forma de organização política" na qual se convive longe da ideia de "domínio" e sem divisão entre "governantes e governados". A essa compreensão da "república", Hannah Arendt acrescenta alguns "elementos que podem ser facilmente reconhecidos na tradição republicana", a saber, a coincidência entre a "república" e o "espaço onde a liberdade se realiza". É indispensável, portanto, que os "cidadãos" participem efetivamente "nos afazeres políticos", para que possam conhecer a "felicidade pública". A "repú- 
blica" é, portanto, o "espaço da ação política" e "permite que os cidadãos deem vazão a seu desejo de distinção e adquiram a 'glória"'. No entanto, apesar da existência de "elementos" da tradição republicana no modo como Hannah Arendt compreende a "república", não se pode negar também, como sublinhou Adverse, que nessa compreensão existe "algo" que não pode ser "contemplado por nenhuma das categorizações usuais no interior da tradição republicana, embora não lhe seja de modo algum oposta". A revolução não se concretiza sem "a constituição de uma república; assim, para Hannah Arendt, a "república" surge "como a forma política própria de uma época secularizada." (ADVERSE, 2012, p. 40-41).

Diferente da Revolução Francesa que "deu novo alento à estrutura política que a precedera", a Revolução Americana rompeu "com a forma de dominação política que vigorava na Europa" e alcançou "sucesso". Os homens da Revolução Americana "foram capazes de criar uma nova ordem secular" e"retirar do processo revolucionário moderno todo o seu potencial emancipatório e completar efetivamente o processo de secularização." (ADVERSE, 2012, p. 45). De todo modo, é preciso registrar que apesar de ter elogiado a Revolução Americana e destacado o seu "sucesso" como a única revolução que, de fato, conseguiu atingir o objetivo de fundar um novo corpo político onde a liberdade possa aparecer, Hannah Arendt aprofunda suas considerações e constata que a Revolução Americana estabeleceu uma nova república, mas a democracia representativa baseada no sistema de partidos políticos adotada pelos Estados Unidos da América, não representa o seu auge, mas sim o seu declínio, uma vez que ela não é tão diferente assim das outras democracias modernas; o seu sistema é também democrático pelo fim que persegue - o bem-estar do povo e a felicidade individual, e oligárquico pelo modo como funciona - liberdade e felicidade públicas são privilégios da minoria. Jefferson, um homem sempre atento aos acontecimentos que sucederam à Revolução Americana e preocupado em garantir a participação do povo no novo governo, "temia um 'despotismo eletivo', que podia ser até pior do que a tirania contra a qual haviam se insurgido". Assim, em uma carta de 16 de janeiro de 1787, dirigida ao Coronel Edward Carrington, ele disse: "Se algum dia o nosso povo se descuidar das coisas públicas, os senhores e eu, o Congresso e as assembleias, os juízes e os governadores, nos transformaremos todos em lobos." (ARENDT, 1988, p. 190). É verdade que o temor de Jefferson não se concretizou nas proporções que ele imaginou, mas a "república" não propiciou ao povo um espaço para a ação política ativa, uma ação que apenas o indivíduo, o "ator" pode desempenhar e que jamais possa ser representada.

O novo corpo político, isto é, "república americana", infelizmente não conseguiu assegurar e perpetuar a sobrevivência do seu princípio inspirador, a saber, "a paixão pela liberdade pública" ou "a busca da felicidade pública". O novo corpo político não conseguiu encontrar um meio eficaz para que tal princípio pudesse ser livremente cultivado pelas "gerações futuras"; ele não foi capaz de estabelecer “instituições que facilitassem 'a felicidade pública' da política participativa." (SCHWARTZ, 1995, p. 192). Portanto, a Revolução Americana teve êxito em fundar um novo corpo político, mas a democracia representativa estabelecida nos Estados Unidos da América, não conseguiu perpetuar o seu princípio inspirador, isto é, não foi capaz de assegurar a discussão incessante em torno dele, para que o mesmo pudesse ser evocado pelas gerações futuras e servir de referência. Para Hannah Arendt, para que as ações dos homens sejam salvas de "sua inerente inutilidade", é preciso discuti-las incessantemente. A Revolução Americana foi coroada de êxito, porque "fundou um novo corpo político", mas não se assegurou a "sobrevivência do espírito que deu origem ao seu ato de fundação" que para Jefferson, era "de suprema importância para a própria sobrevivência do novo corpo político." (ARENDT, 1988, p. 101).

Não havia dúvida entre os homens da Revolução Americana, que a liberdade era uma felicidade pública e não um fardo, todos estavam cientes que se tratava de participar 
no governo, mas nota-se, de acordo com observações de Hannah Arendt, que a "Declaração de Independência fala da 'busca da felicidade' e não da 'felicidade pública'". Essa "alteração" que passou despercebida entre aqueles homens que participaram dos debates da assembleia acabou permitindo que cada uma das sucessivas gerações se sentisse totalmente "livre" para interpretar a expressão "busca da felicidade" da maneira que melhor lhe conviesse (ARENDT, 1988, p. 102). Portanto, a própria Declaração de independência, da maneira como foi redigida, contribuiu para tornar imprecisa ou ambígua a "distinção entre felicidade pública e privada" (ARENDT, 1988, p. 105). Faltou resolver a questão referente ao objetivo do novo corpo político; em outras palavras, não ficou claro se o seu objetivo seria liberdade ou prosperidade.

Devido a esse impasse, os cidadãos americanos buscaram a felicidade privada, enveredando-se pelo sonho da opulência e do consumo. $O$ "ideal republicano de liberdade e justiça para todos os cidadãos", como disse diz McCarthy, em seus estudos, "se converteu no sonho burguês da terra que emana leite e mel, um empreendimento econômico sem controle onde todo o mundo podia tornar-se rico." (MCCARTHY, 2000, p. 154). Na América, após a perda da paixão pela "liberdade pública" ou "felicidade pública" que inspirou os homens da revolução, restaram apenas "as liberdades civis, o bem-estar individual da grande maioria da população, e, além disso, a opinião pública como a força mais poderosa a dirigir uma sociedade democrática e igualitária". Para Hannah Arendt, tudo isso surge, de um modo geral, "como se os princípios, originalmente políticos, fossem traduzidos em valores sociais." (ARENDT, 1988, p. 177). A Revolução Americana não conseguiu institucionalizar um espaço de participação política direta para a busca da "felicidade pública", cujo prazer não se relaciona com a ânsia pelo poder, mas com o simples ato de participar do domínio público; esse tipo de felicidade, não é e nem pode ser concebida como sentimento de satisfação pela vitória obtida sobre um adversário e nem como orgulho demonstrado por aqueles que fazem parte de uma elite privilegiada da sociedade, mas sim como uma felicidade compartilhada, a felicidade de ser livre entre outras pessoas livres, recuperar e salvar a nossa "fé pública", ver a "esperança pública" se convertendo em "poder público." (LUMMIS, 2002, p. 206-207).

Jefferson percebeu essa falha com certa clareza e chamou atenção para a divisão de república em "repúblicas elementares ou conselhos no sentido de renovar o princípio revolucionário da geração fundadora." (BERNSTEIN, 1996, p. 130). Sua intenção era que cada um fizesse parte de algum conselho, seja grande ou pequeno, como forma de assegurar o seu poder. Na nova ordem política, a Constituição não incorporou os "municípios" e as "câmaras municipais, fontes originais de toda a atividade política do país", impossibilitando a participação pública como essência da liberdade (ARENDT, 1988, p. 191). A Constituição fez justiça "ao poder, ao juízo, à opinião, aos direitos, aos interesses, às qualidades que permitem 'construir o edifício"', mas ela ignorou "a ação e as suas potencialidades" e não deixou "espaço às qualidades que permitiram a construção." (AMIEL, 2003, p. 92). O direito de cada cidadão de participar ativamente no governo se confundiu com as liberdades individuais e civis que impossibilitaram o povo alcançar a "felicidade pública". A liberdade em seu sentido mais alto, não foi o preço pago pela "fundação" do novo corpo político; "foi a própria Constituição, a maior conquista do povo americano, que acabou privando-o de sua mais valiosa conquista." (ARENDT, 1988, p. 191). A Revolução Americana não proporcionou ao povo um verdadeiro espaço público acessível para que ele pudesse exercer e desfrutar ativamente da sua liberdade. $A$ "felicidade pública" é "privilégio" de poucos, e apenas estes se engajam, de fato, "nas atividades de 'expressão, discussão e decisão', as quais, num sentido positivo, são as atividades da liberdade." (ARENDT, 1988, p. 188). 


\section{Referências}

ADVERSE, Helton. Uma república para os modernos. Arendt, a secularização e o republicanismo. Filosofia Unisinos, v.13, n.1, p.39-56, jan/abr, 2012.

AMIEL, Anne. Hannah Arendt: política e acontecimento. Tradução de Sofia Mota. Lisboa: Piaget, 1997.

AMIEL, Anne. A não-filosofia de Hannah Arendt: revolução e julgamento. Tradução de João C. S. Duarte. Lisboa: Piaget, 2003.

ARENDT, Hannah. A condição humana. Tradução de Roberto Raposo. Rio de janeiro: Forense, 2009a. ARENDT, Hannah. Entre o passado e o futuro. Tradução de Mauro Barbosa de Almeida. São Paulo: Perspectiva, 1972.

ARENDT, Hannah. Da revolução. Tradução de Fernando Dídimo Vieira. Brasília: UnB, 1988.

BERNSTEIN, Richard. Hannah Arendt and the jewish question. Cambridge: MIT Press, 1996.

KING, Richard. Arendt and America. Chicago: The University of Chicago Press, 2015.

LANG, Anthony. Governance and political action: Hannah Arendt on Global Political Protest. In: LANG, Anthony \& WILLIAMS, John (Eds). Hannah Arendt and international relations: reading across the lines. New York: Palgrave Macmillan, 2005.

LUMMIS, Douglas. Democracia radical. Tradução de Susana Guardado del Castro. Buenos Aires: Siglo XXI Editores, 2002.

MCCARTHY, Michael. El pensamiento político de Hannah Arendt. Lima: Antonio Ruiz de Montoya, 2000.

PAREKH, Bhikhu. Hannah Arendt and the search for a new political philosophy. London: Macmillan, 1981.

SCHWARTZ, Joseph. Hannah Arendt's politics of "action": the elusive search for political substance. In: The permanence of the political: a democratic critique of the radical impulse to transcend politics. Princeton: Princeton University Press, 1995.

WILKINSON, Michael. Between freedom and law: Hannah Arendt on the promise of modern revolution and the burden of the tradition. In: GOLDONI, Marco \& MCCORKINDALE, Christopher (Eds.). Hannah Arendt and the Law. Oxford: Hart Publishing, 2012.

WINTERS, Francis. Banality of virtue: reflections on Hannah Arendt's reinterpretation of political ethics. In: BERNAUER, James (Ed.). Amor mundi: explorations in the faith and thought of Hannah Arendt. Boston: Martinus Nijhoff, 1987.

Sobre o autor

José João Neves Barbosa Vicente

Doutor em Filosofia, professor adjunto de Filosofia da UFRB.

Recebido em: 22/6/2019

Aprovado em: 19/11/2019 